\title{
Mechanism of metastasis suppression by luteolin in breast cancer
}

This article was published in the following Dove Press journal:

Breast Cancer - Targets and Therapy

\section{Matthew T Cook}

Department of Biology, Washburn University, Topeka, KS, USA
Correspondence: Matthew T Cook Department of Biology, Washburn University, I 700 Southwest College Avenue, Topeka, KS 6662I, USA

Tel + I 7856701740

Email matthew.cook@washburn.edu

\begin{abstract}
Metastatic breast cancer is typically an extremely aggressive cancer with poor prognosis. Metastasis requires the orchestration of homeostatic factors and cellular programs, many of which are potential therapeutic targets. Luteolin (2-[3,4-dihydroxyphenyl]-5,7-dihydroxy4-chromenone), is a naturally occurring flavonoid found in fruits and vegetables that exhibits many anticancer properties. Luteolin obstructs metastasis through both direct and indirect mechanisms. For instance, luteolin may suppress breast cancer invasion by acting as an antiangiogenic therapeutic inhibiting VEGF production and its receptor's activity. Furthermore, luteolin decreases epithelial-mesenchymal transition markers and metastatic proclivity. Luteolin also acts as an antiproliferative by suppressing receptor tyrosine-kinase activity and apoptosis, both of which could prevent incipient colonization of breast cancer. Many of these antimetastatic characteristics accredited to luteolin are likely functionally related. For instance, the PI3K/Akt pathway, which is impeded by luteolin, has several downstream programs involved in increased proliferation, survival, and metastatic potential in breast cancer. In this review, luteolin's ability to ameliorate breast cancer is summarized. The paper also offers insight into the molecular mechanisms by which luteolin may suppress breast cancer metastasis.
\end{abstract}

Keywords: angiogenesis, MMP, NOTCH, $\beta$-catenin, RTK, Akt

\section{Introduction}

Breast cancer afflicts millions of women worldwide and is the second-leading cause of cancer related death in US women. ${ }^{1}$ Early detection, awareness, and treatment options have significantly improved quality of life in breast cancer survivors. Over a century ago, Paget postulated that metastatic cancer is not determined by chance, but instead depends upon coordinated crosstalk between circulating tumor cells (seeds) and organ-specific microenvironments (soil). ${ }^{2}$ In agreement with Paget's hypothesis, metastatic breast cancer tends preferentially to metastasize to the bone, brain, liver, and lungs. Only 5\%-10\% of all new cancers are diagnosed as metastatic, ${ }^{1}$ and the lack of therapeutic options likely explains why $90 \%$ of cancer-related deaths are attributed to metastasis and not primary tumor encumbrance. ${ }^{1,3,4}$ Preventing tumor metastasis is arguably the paramount challenge to curing cancer, as well-defined localized tumors are manageable with current options.

All potential secondary tumors must first invade, disseminate, and subsequently colonize a hostile environment. ${ }^{3,5}$ These biological events are orchestrated through intrinsic and extrinsic homeostatic factors and molecular pathways, of which many may provide clinical opportunities to mitigate the metastatic propensity of breast cancer. Currently, most chemotherapeutic approaches revolve around obstructing established 
and incipient tumors through a combination of surgical resection and adjuvant therapy. These therapies have exceptional outcomes for breast cancer patients with confined primary tumors; however, metastatic cancer, being systemic in nature and resistant to chemotherapeutics, tends to have poorer prognosis. ${ }^{6}$ This article addresses the aptitude of luteolin (2-[3,4-fihydroxyphenyl]-5,7-dihydroxy-4-chromenone), a natural occurring flavonoid found in fruit and vegetables ${ }^{7}$ (Figure 1), to combat metastatic breast cancer by focusing on research that exemplifies the capacity of luteolin to abrogate metastatic steps involved in invasion, migration, and colonization (Table 1).

\section{Angiogenesis}

The invasion-metastasis cascade begins with neovascularization, the transition from epithelial to mesenchymal subtype, and the dissolution of the proteinaceous extracellular matrix and basement membrane. ${ }^{8}$ The "angiogenic switch" in carcinogenesis increases potent angiogenic factors, such as platelet-derived growth factor (PDGF) and vascular endothelial growth factor (VEGF), increasing tumorigenicity. ${ }^{9-11}$ VEGF plays an instrumental role in tumor-cell survival, proliferation, and migration. ${ }^{9-13}$ As such, luteolin significantly reduces VEGFA production in MDA-MB-231 triple-negative breast cancer cells, which lack ER, PR, and HER2 (aka HER2/ neu). ${ }^{14,15}$ An antibody blockade against VEGFR-2, a receptor tyrosine kinase (RTK), has produced results similar to that of luteolin; ${ }^{14}$ however, a causative link was not established. An in vivo study using progestin-driven T47D breast cancer cells showed that luteolin significantly reduced progestinstimulated blood vessel formation. ${ }^{16}$ A similar reduction in blood vessel formation by luteolin is seen in prostate cancer xenografts. ${ }^{17}$ Luteolin has also been reported in two unrelated studies to reduce MDA-MB-231 lung metastasis in nude mice, ${ }^{14,18}$ which in part may be attributed to reduced blood vessel formation.

One plausible explanation for the reduction in bloodvessel formation is that luteolin suppresses endothelial cell

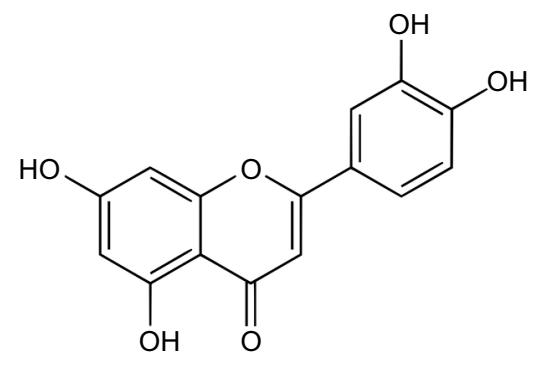

Figure I Chemical structure of luteolin. proliferation and migration, a necessity for angiogenesis and nascent tumor growth. ${ }^{12}$ Interestingly, MDA-MB-231conditioned media from cells treated with luteolin reduced tube formation and cell migration in human umbilical vein endothelial cells (HUVECs). ${ }^{15}$ A gastric cancer study reported luteolin reduced VEGF production in both gastric cancer cells and HUVECs, as well as reduced endothelial cell migration and proliferation. ${ }^{19}$ Furthermore, luteolin prevented cancer-promoting effects when cocultured with HUVECs and gastric cancer cells. ${ }^{19}$ Prospectively, this reduced migratory potential may be attributed to luteolin's efficacy to inhibit VEGF-induced PI3K activity by blocking Akt phosphorylation. ${ }^{14,20}$ In separate studies, luteolin suppressed VEGF and angiotensin II-induced endothelial cell migration through the downregulation of VEGFR-2 phosphorylation ${ }^{21}$ and the PI3K/Akt pathway. ${ }^{22}$ Another article regarding endothelial cells showed that luteolin decreased VEGF-induced VEGFR-2 phosphorylation and downstream effectors, such as Akt (Figure 2). ${ }^{17}$ Pratheeshkumar et al showed that luteolin reduced kinase activity and proinflammatory cytokines in prostate cancer in vitro. ${ }^{17}$ Taken together, these reports provide a potential relationship between the ability of luteolin to obstruct VEGF-induced angiogenesis and the prospective colonization of metastatic sites. Speculatively, this relationship may be due to luteolin impeding paracrine signaling between tumors and their microenvironment. However, the mechanism of action needs further research to determine the involvement of VEGF and luteolin in suppression of metastatic breast cancer cells.

\section{Membrane degradation}

A key step in neovascularization and tumor invasion is the degradation of the basement membrane, which is facilitated by matrix metalloproteinases (MMPs). ${ }^{23,24}$ In breast cancer, deregulation of MMP expression promotes invasion and metastasis. ${ }^{25}$ In particular, several studies implicate MMP-2 and MMP-9 in enabling progression through the metastatic cascade, and MMP-9 being a possible prognostic factor for invasive breast cancer. ${ }^{25}$ An early kinetic analysis characterized luteolin as a potent non-competitive inhibitor of MMP-9. ${ }^{26}$ Recent evidence reported in MCF7 and MDA-MB-231 cells confirms the ability of luteolin to decrease both MMP-2 and MMP-9 mRNA and protein expression significantly. ${ }^{15}$ Likewise, treatment of 12-O-tetradeconylphorbol-13-acetatetreated MCF7 cells with a luteolin derivative mitigated MMP-9 expression and subsequently reduced the invasive potential of these breast cancer cells. ${ }^{27}$ Park et al attributed the reduced invasive potential to the downregulation of the MAPK 
Table I Effect of luteolin on breast cancer at a glance

\begin{tabular}{|c|c|c|c|}
\hline Cell line & Target & Effect & Reference \\
\hline $\begin{array}{l}\text { MDA-MB-435, MDA- } \\
\text { MB-23I* }\end{array}$ & VEGF/VEGFR-2 & Decreased VEGF, cell migration, lung-nodule formation & 14 \\
\hline MDA-MB-23I, MCF7 & $\begin{array}{l}\text { Notch I, VEGF, } \\
\text { MMP-2, MMP-9 }\end{array}$ & Reduced invasion potential, Notch I, VEGF, and MMPs & 15 \\
\hline T47D, BT-474 & VEGF & $\begin{array}{l}\text { Suppressed progestin-induced VEGF, blood vessel, stem-like properties, and } \\
\text { tumorigenicity }\end{array}$ & 16 \\
\hline MDA-MB-23I, BT549 & Wnt/ $\beta$-catenin & Decreased $\beta$-catenin, Snail, Slug, vimentin, $\mathrm{N}$-cadherin, and lung-tumor nodules & 18 \\
\hline MCF7 & MMP-9, IL-8, ERK & $\begin{array}{l}\text { Decreased TPA-induced migration and invasion, MMP-9, IL-8, and ERK, NF- } \mathrm{KB} \text {, } \\
\text { and c-Jun activity }\end{array}$ & 27 \\
\hline MCF7 & AEG-I, MMP-2 & Decreased cell migration and AEG-I and MMP-2 protein levels & 29 \\
\hline MDA-MB-23I, SUM-I49 & RSK/YBI, Notch4 & Inhibited RSK, Notch4, pGSK-3 $\beta$, and YB-I activation & 39 \\
\hline MDA-MB-23I & EGFR/MAPK & $\begin{array}{l}\text { Decreased Akt, PLKI, cyclin BI, cyclin A, CDK2, Bcl-xL, and EGF-induced pEGFR; } \\
\text { increased } \mathrm{p} 2 \mathrm{I} \text { and Bax }\end{array}$ & 61 \\
\hline MCF7* & $\begin{array}{l}\text { p21, p38, p53, } \\
\text { cyclin DI }\end{array}$ & Induced p2I, p38, and p53; reduced cyclin DI & 62 \\
\hline MDA-MB-453 & HER2, Akt, S6K & $\begin{array}{l}\text { Decreased HER2 and p2I, upregulated p27; increased p2I, transient suppression } \\
\text { of Akt except at highest dose }\end{array}$ & 63 \\
\hline MDA-MB-453 & HER2 & Decreased HER2/neu protein expression & 74 \\
\hline MCF7 & DR5, Bcl-2 & $\begin{array}{l}\text { Enhanced DR5 and caspase } 8 / 9 / 3 \text {, inactivated PARP, increased Bax, and inhibited } \\
\text { Bcl-2 }\end{array}$ & 76 \\
\hline MCF7 & EGFR & Suppressed EGF-induced pEGFR, Akt, pErkI/2, pSTAT3 & 84 \\
\hline MDA-MB-23I & STAT3 & $\begin{array}{l}\text { Paclitaxel combined therapy increased apoptosis, inhibited STAT3, increased FAS } \\
\text { expression }\end{array}$ & 87 \\
\hline MCF7 & IGFR, Akt, ER $\alpha$ & $\begin{array}{l}\text { Decreased IGF-induced pIGFR, Akt, and ER } \alpha \text {, but not ERK; silencing ER } \alpha \\
\text { mitigated effects. }\end{array}$ & 91 \\
\hline MCF7 & PKLI & E2 combination therapy blocked PKLI expression & 96 \\
\hline MCF7 & Akt & $\begin{array}{l}\text { Reduced doxorubicin-induced cytotoxicity, increased Akt and Bcl-2 protein } \\
\text { expression }\end{array}$ & 98 \\
\hline $\begin{array}{l}\text { MDA-MB-23I, } \\
\text { HS-578T, MCF7 }\end{array}$ & Akt, p53, FOXO & $\begin{array}{l}\text { Increased p53 and cytochrome C; cleaved PARP, nFOXO3a, p2I, and p27; } \\
\text { inhibited cell migration, pAkt, and cFOXO3a }\end{array}$ & 101 \\
\hline MDA-MB-23I & p53 & Decreased $\mathrm{Bcl}-2$ mRNA expression and increased p53 & 102 \\
\hline MDA-MB-23I, MCF7 & Akt & Increased apoptosis, decreased Akt & 105 \\
\hline MDA-MB-23I & FAS & $\downarrow$ FAS and cell viability & 109 \\
\hline MDA-MB-23I & $\begin{array}{l}\text { nAChR, AKT, ERK, } \\
\text { NFKB }\end{array}$ & $\begin{array}{l}\text { Decreased nicotine-induced } \alpha 9-n A C h R, A K T \text {, ERK, and NF-KB-induced } \alpha 9 \text { - } \\
\text { nAChR luciferase activity }\end{array}$ & 117 \\
\hline MDA-MB-23I, MCF7 & Cyclin E2 & Reestablished tamoxifen efficacy; reduced cyclin E2 & 119 \\
\hline MCF7* & MRP & GSX pump inhibition & 120 \\
\hline MDA-MB-23I & cMet & Decreased cMet levels & 121 \\
\hline $\begin{array}{l}\text { MCF7, SKBR3, MDA- } \\
\text { MB-23I }\end{array}$ & AIF, ERK, p38 & $\begin{array}{l}\text { Increased ERK, p38 protein, and caspase 3; cleaved PARP; decreased AIF nuclear } \\
\text { localization }\end{array}$ & 122 \\
\hline MCF7 & Glycolysis & Reversed hypoxia-induced doxorubicin resistance & 123 \\
\hline
\end{tabular}

Note: *Variant cell line.

pathway resulting in suppression of the proliferative transcription factors AP-1 and NF- $\kappa \mathrm{B} .{ }^{27} \mathrm{MMPs}$ promote cancer progression by cleaving an array of growth-factor precursors, which increases cell proliferation, invasion, and metastasis. ${ }^{28}$ The link between luteolin-driven inhibition of MMPs and decreased metastatic potential is also seen in various other models, ${ }^{29-32}$ and thus warrants further investigation into the mechanism of action for luteolin-induced MMP inhibition.

MMP-mediated degradation of the extracellular matrix releases numerous growth factors and signaling molecules that enable tumor expansion. ${ }^{33}$ One such factor normally sequestered in the matrix is the ubiquitous hyaluronic acid (HA). HA is degraded by hyaluronidase into various molecular weights, which then potentiates tumor progression and angiogenesis through one of two receptors: CD44 and RHAMM. ${ }^{34}$ In breast cancer, the cell-surface proteins' CD $44^{+} / \mathrm{CD} 24$ profile is indicative of cancer stem-cell-like properties ${ }^{35}$ and increased metastatic potential. ${ }^{36,37}$ Luteolin has been shown to be a potent inhibitor of hyaluronidase at relatively high concentrations ${ }^{38}$ and to prevent progestin-induced increases 


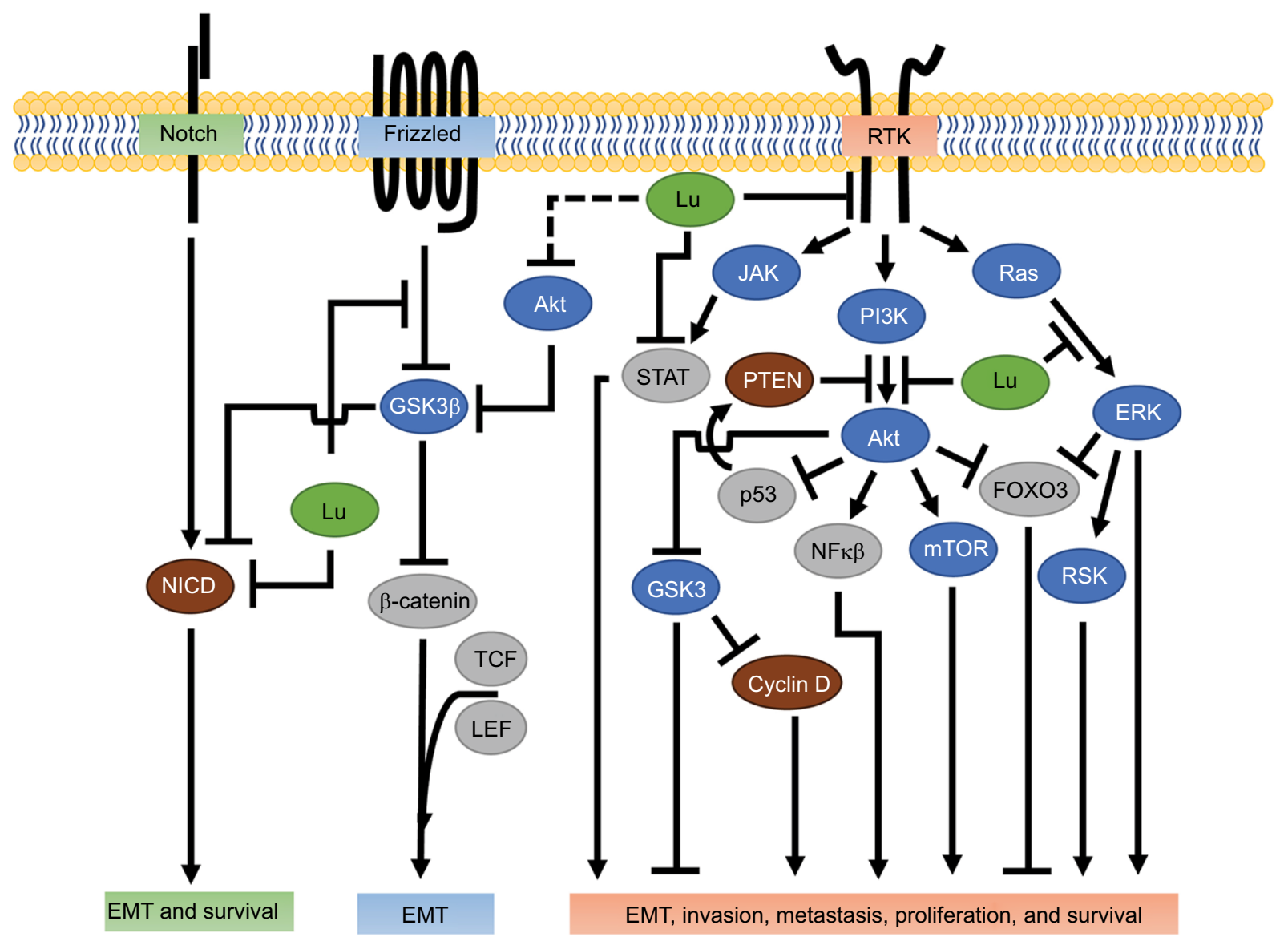

Figure 2 Luteolin inhibition of receptor-mediated tumor progression.

Notes: Involvement of luteolin (green) in modifying processes necessary for metastasis. Notch activation results in removal of the intracellular domain of the membranebound Notch receptor, creating the NICD. NICD is blocked by luteolin through an undetermined mechanism. Wnt/ $\beta$-catenin inhibits GSK3 activity upon activation. Luteolin blocks Wnt-induced phosphorylation of GSK3, and thus prevents GSK3 inhibition. Luteolin has been shown to inhibit RTK activities and their downstream effectors (see text for specific RTKs and associated effector responses). Possible outcomes for each receptor pathway are in the corresponding colored boxes. Intracellular proteins colorcoded as protein kinases (blue), TCFs (gray), and other proteins (brown). Dashed line represents possible luteolin interaction.

Abbreviations: EMT, epithelial-mesenchymal transition; JAK, Janus kinase; Lu, luteolin; NICD, notch intracellular domain; RSK, ribosomal S6 kinase; RTK, receptor tyrosine kinase; TCF, transcription factor.

in $\mathrm{CD} 44^{+}$expression and ALDH activity at low doses. ${ }^{16}$ In a combination treatment, luteolin prevented paclitaxel-induced CD $44^{+}$enrichment. ${ }^{39}$ Along the same lines, luteolin has been reported to reduce $\mathrm{CD}_{4} 4^{+}$expression in prostate cancer, ${ }^{40}$ as well as reduce $\mathrm{CD} 44^{+}$and $\mathrm{ALDH}$ activity in oral cancer cells. ${ }^{41}$ These observations provide evidence suggesting that luteolin may prevent breast cancer cells from transitioning to a more tumorigenic stem-cell-like phenotype, though the exact mechanism is unknown.

\section{Tumor microenvironment}

The tumor microenvironment is involved in numerous aspects of tumorigenicity. ${ }^{42,43}$ Cancer cells interact with surrounding fibroblast, stromal, immune, and endothelial cells through paracrine factors that promote angiogenesis, membrane degradation, epithelial-mesenchymal transition (EMT), colonization, and cancer stem-cell upkeep. ${ }^{8,43}$ Luteolin, a known anti-inflammatory and antioxidant, ${ }^{44}$ potentially modifies the tumor microenvironment. As described, luteolin decreases VEGF production, MMPs, and endothelial migration, all of which promote tumor progression. In breast cancer, cytokines coordinate communication between cancer cells and the microenvironment. ${ }^{43}$ Recent evidence showed a luteolin derivative suppressed 12-O-tetradeconylphorbol-13-acetateinduced IL- 8 mRNA expression. ${ }^{27}$ The authors attributed the reduction in IL-8, a chemokine associated with advancedstage breast cancer, ${ }^{45}$ to MAPK inhibition. ${ }^{27}$ In pancreatic cancer, luteolin has been shown to reverse IL-6-stimulated EMT by inhibiting STAT3 signaling. ${ }^{32}$ Similarly, luteolin prevents IL-6/STAT3 signaling in oral cancer. ${ }^{41}$ In a murine model, luteolin suppressed tumor-associated macrophage (TAM) secretion of promigratory chemokine CCL2 (aka MCP1) and attenuate CCL2-induced Lewis lung carcinomacell migration. ${ }^{46}$ In general, TAMs and other tumor-associated 
immune cells promote metastasis through release of growth factors and cytokines, the latter of which may recruit more immune cells, resulting in signal amplification. ${ }^{43}$ In light of this research, luteolin's ability to reduce cytokine secretion from TAMs may contribute to the perturbation of metastasis. However, the nature by which luteolin arbitrates communication between breast cancer cells and the "soil" remains unclear.

\section{Wnt/ $\beta$-catenin signaling}

The Wnt/ $\beta$-catenin pathway plays a crucial role in morphogenesis and EMT. ${ }^{47,48}$ EMT is strongly associated with increased stem-cell-like properties like self-renewal, and is essential for development of breast cancer metastasis. ${ }^{47}$ EMT progression requires concomitant activity of various signaltransduction pathways, such as the Wnt/ $\beta$-catenin pathway. ${ }^{49}$ In the canonical Wnt pathway, an unbound receptor allows for intracellular GSK3 $\beta$ to phosphorylate $\beta$-catenin and initiate proteolytic degradation, thereby reducing $\beta$-catenin levels. ${ }^{50}$ In contrast, when Wnt conjugates with its receptor, GSK3 $\beta$ activity decreases, enabling $\beta$-catenin accumulation and its nuclear localization, resulting in increased $\beta$-cateninorchestrated transcriptional activity and gene expression. ${ }^{50,51}$ Recent evidence has shown that luteolin effectively reduces $\beta$-catenin mRNA and protein levels in the triple-negative breast cancer cell lines MDA-MB-231 and BT-549. ${ }^{18}$ Lin et al further showed that luteolin was associated with downregulation of the EMT markers Slug, N-cadherin, vimentin, and Snail and upregulation of the epithelial marker E-cadherin, reinforcing luteolin's antimetastatic potential. ${ }^{18} \mathrm{Wnt} / \beta$-catenin signaling can result in high nuclear Snail expression driving EMT; furthermore, the inverse relationship between Snail and E-cadherin is indicative of poor breast cancer prognosis. ${ }^{52}$ As such, Lin et al suggested that the anti-EMT capacity of luteolin was mediated through $\beta$-catenin. ${ }^{18}$ They supported this hypothesis in vitro and in vivo with the observation that overexpression of $\beta$-catenin rescued the migratory capacity of MDA-MB-231 cells in the presence of luteolin. ${ }^{18}$ Of similar note, in colon cancer cells luteolin reduced the expression of the transcriptionally active forms of $\beta$-catenin and the phosphorylation of GSK3 $\beta$ (Figure 2). ${ }^{53}$ These data suggest that luteolin may act through the $\mathrm{Wnt} / \beta$-catenin signaling pathway to suppress EMT, a pinnacle step in invasion and metastasis.

\section{Notch signaling}

In breast cancer, Notch signaling potentiates EMT through a variety of pathways, including Wnt/ $\beta$-catenin, TGF $\beta$, and the RTKs. ${ }^{48,54}$ Ligand-receptor-bound Notch initiates the cleavage of Notch intracellular domain (NICD) which then relocates to the nucleus, where it complexes with transcriptional activators that regulate Myc, p21, Hey1, and Hes1. ${ }^{48}$ Luteolin suppresses Notch1 signaling and its downstream effectors Hes1 and Hey1 in MDA-MB-231 and MCF7 breast cancer cells. ${ }^{15}$ These findings are of particular interest, because Hes 1 inhibits the tumor-suppressor PTEN and Hey1 promotes EMT genes, ${ }^{55}$ so suppressing Hes 1 and Hey1 would likely translate to decreased metastatic propensity.

Reipas et al found that in SUM-149 cells enriched for stem-cell-like properties (CD44 $\left.{ }^{+} / \mathrm{CD} 24^{-}\right)$, luteolin inhibited Notch 4 , with associated loss in cell viability and mammosphere formation. ${ }^{39}$ In that study, luteolin acted as a novel p90 ribosomal S6 kinase (RSK) inhibitor in breast cancer cells. ${ }^{39}$ The RSK family of proteins are highly conserved downstream effectors of the ERK/MAPK signaling pathway, and regulate cell survival, proliferation, and migration. ${ }^{56}$ Also in Reipas et al, in MDA-MB-231 cells, RSK inhibition was accompanied by attenuation of the downstream-transcription factor YB-1 and an associated reduction in Notch4 mRNA signaling. siRNA knockdown of YB-1 resulted in a marked decrease in Notch4 and an associated loss in the NICD, implicating possible mediation between YB-1 and Notch4. Interestingly, the authors noted that siRNA knockdown of YB-1 also increased Notch1 mRNA transcripts; however, they did not attribute this effect to luteolin treatment. ${ }^{39}$ Taken together, these studies implicate both Notch1 and Notch4 as possible targets by which luteolin could regulate the metastatic potential of breast cancer, which is encouraging, because the inhibition of Notch4 signaling has been shown to abolish breast cancer tumor formation in vivo completely. ${ }^{57}$

The Notch and Wnt/ $\beta$-catenin pathways crosstalk, specifically through GSK $3 \beta .{ }^{55}$ GSK3 $\beta$-dependent phosphorylation of the NICD effectively inhibits transcriptional activation of Notch target genes in vitro and in vivo. ${ }^{58}$ Luteolin attenuates GSK3 $\beta$ inactivation in the $\mathrm{Wnt} / \beta$-catenin pathway, ${ }^{53}$ and because Akt is known to inactivate GSK $3 \beta,{ }^{59}$ it is plausible to suspect that luteolin-induced NICD decrease may be the result of Akt inhibition and increased GSK $3 \beta$ activity. The ability of luteolin to suppress NICDs may be through direct interaction, indirectly through RSK/YB-1, or by preventing inactivation of GSK3 $\beta$ (Figure 2). Luteolin's capacity to mitigate NICD signaling and by extension metastatic potential could correlate with improved quality of life in breast cancer patients.

\section{Antiproliferation capability of luteolin}

In the later steps of the metastatic cascade, metastatic "seeds" must extravasate and colonize new tissue. During 
colonization, cells transition from a quiescent state to a proliferative state under the control of the cell cycle. The cell cycle controls mitotic division and is regulated through cyclin-dependent kinases (CDKs), cyclins, and their inhibitors p21 (p2 $\left.{ }^{\text {Cip1 }}\right)$ and p27 (p27 $\left.{ }^{\text {Kipl }}\right){ }^{60}$ Deregulation of cellcycle proteins, such as in upregulation of CDKs in normal mammary tissue, can cause breast cancer. ${ }^{60}$

In light of this, luteolin has been shown to cause cell cycle arrest in many different cancers. In MDA-MB-231 cells, luteolin prevented ${ }^{3} \mathrm{H}$-thymidine DNA incorporation and arrested cells in the cell cycle $\mathrm{G}_{2} / \mathrm{M}$ phase. ${ }^{61}$ Further analysis of cell cycle-dependent regulatory proteins showed that luteolin induced an increase in $\mathrm{p} 21$ expression, as well as an associated suppression of S-phase cell-cycle modulators cyclin A and CDK2 and M-phase protein cyclin B1. ${ }^{61}$ Intriguingly, luteolin shows a biphasic response, causing an increase in $\mathrm{p} 21$ at low $\operatorname{doses}^{61,62}$ and a decrease in $\mathrm{p} 21$ at higher doses.$^{63} \mathrm{P} 21$, a major target of the tumor suppressor p53, inhibits CDK2 preventing cell cycle progression and promotes cell survival, though the latter is dependent upon Akt inhibition of p21 nuclear translocation. ${ }^{61,64}$ Cotreatment of luteolin with p21 siRNA mitigates p21-induced survival advantage. ${ }^{63}$ The observed increase in p21 is likely due to luteolin-induced Akt inhibition (Figure 3); ${ }^{61}$ however, other possibilities include the ability of luteolin indirectly to modify $\mathrm{p} 53$ activity by suppressing DNA topoisomerases I and II (essential DNA-repair proteins) ${ }^{65-67}$ and stabilizing $\mathrm{p} 53,{ }^{68}$ or by a loss of negative feedback from CDK2. ${ }^{69}$ Either way, luteolin-mediated regulation of $\mathrm{p} 21$, CDKs, and cyclins potentiates cell cycle arrest in breast cancer cells. ${ }^{53,65,70,71}$ However, more studies are necessary to elucidate the biphasic response of luteolin on p21 and whether or not luteolin induces changes in p21 localization.

\section{Human epidermal growth-factor receptor 2}

The HER family consists of four membrane-bound transmembrane receptors, and is associated with cell survival, proliferation, and metastasis in breast cancer. ${ }^{72}$ Once a ligand binds to a HER receptor other than an orphan receptor, it preferentially dimerizes with HER 2 and subsequently

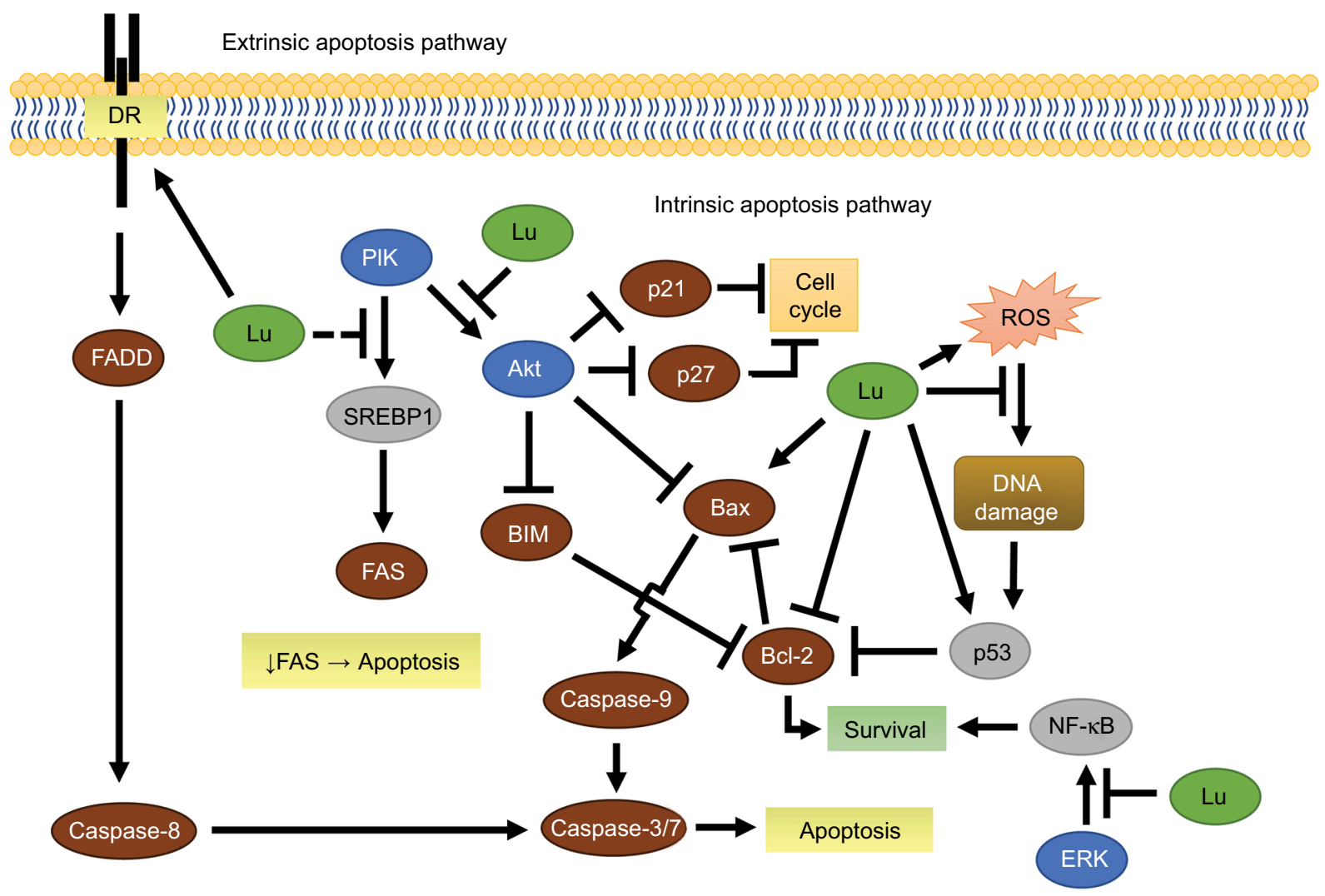

Figure 3 Luteolin-mediated extrinsic and intrinsic apoptosis in breast cancer.

Notes: Illustration abridging the involvement of luteolin (green) in purposed apoptotic pathways. Luteolin sensitized the DR, activated caspase 8, and induced caspase 3-mediated apoptosis. Decreased FAS activity directly or indirectly by luteolin leads to apoptosis through an unknown mechanism. Inhibition of Akt or ERK leads to increased activity in the intrinsic apoptosis pathway. Circumstantially, luteolin acts as an antioxidant or drives ROS-mediated apoptosis. Intracellular proteins color-coded as protein kinases (blue), TCFs (gray), and other proteins (brown). Dashed line represents possible luteolin interaction. Abbreviations: DR, death receptor; Lu, luteolin; ROS, reactive oxygen species; TCFs, transcription factors. 
activates the downstream effectors PI3K/Akt and mTOR. ${ }^{73}$ HER2 overexpression is diagnosed in approximately $20 \%-25 \%$ of all new breast cancer cases, and even though targeted therapy exists, HER2 breast cancers are associated with poorer prognosis. ${ }^{73}$ In MDA-MB-453 breast cancer cells, luteolin at low concentrations has increased HER2 protein degradation in two separate reports. ${ }^{63,74}$ Chiang et al reported that luteolin inhibited cell proliferation, upregulated p27, and downregulated p21 at high doses. ${ }^{63} \mathrm{P} 27$ regulates cell-cycle progression, and low levels of p27 are typically associated with poorer prognosis in breast cancer patients. ${ }^{75}$ The beneficial properties of increased cytosolic p27 may depend upon compartmentalization, as Akt inhibits p27 through Akt-mediated nuclear exclusion, preventing p27-induced cell cycle inhibition (Figure 3). Investigation into MDA-MB-453 cells showed that low/high doses of luteolin, respectively, induced transient and complete suppression of Akt and its effector mTOR. ${ }^{63}$ Akt resurgence is prevented when low dose luteolin is coincubated with rapamycin, an mTOR inhibitor, suggesting Akt/mTOR involvement. Additional studies have shown that moderate-high doses of luteolin resulted in decreased cyclin D1 (a principal regulator of $\mathrm{G}_{1} / \mathrm{S}$ cell cycle transition $)^{62}$ and increased p27 accumulation. ${ }^{63,76}$

In general, HER2-driven tumors are considered "oncogene-addicted", meaning that without the oncogene, they cannot survive. ${ }^{77}$ Unfortunately, targeting these addicted cancers with TK inhibitors (TKIs) has proven only moderately successful, due to the HER2-driven cancers developing resistance. ${ }^{77}$ Recent evidence has shown that the transient effect of TKIs may be due to Akt-mediated negative feedback resulting in HER3 recruitment and thus PI3K/Akt signal restoration. ${ }^{77}$ A report using trastuzumab, a HER2 antibody, blockade resulted in suppressed Akt and cyclin D1 activity, with a corresponding increase in p27 in BT-474 and SKBR3 cells, but not in MDA-MB-361 or MDA-MB-453 breast cancer cells. ${ }^{78}$ This suggests that the efficacy of TKIs is contingent on whether HER2 inhibition is followed by PI3K/Akt attenuation, and whether or not the TKI can sustain Akt inhibition. ${ }^{78}$ In combination therapy, luteolin synergistically enhances lapatinib, a HER2 and epidermal growth-factor receptor (EGFR) inhibitor, and inhibits Akt- and ERK-signaling pathways, resulting in decreased cell proliferation. ${ }^{79}$ Interestingly, unlike luteolin, the PI3K inhibitor LY294002 causes complete Akt suppression over 24 hours, but only marginally decreases cyclin D1 in MDA-MB-453 cells. ${ }^{63}$ These studies suggest that luteolin may arrest cells by suppressing HER2 signaling through the PI3K/Akt and ERK/MAPK pathways, which may prove advantageous in preventing TKI resistance in breast cancer. The ability of luteolin to degrade HER2, reduce Akt activity, and arrest cells will reduce metastatic potential by preventing incipient colonization.

\section{EGFR}

EGFR (aka HER1) is an HER-family transmembrane RTK that relays signals through the JAK/STAT, PI3K/Akt, and MAPK-signaling pathways that ultimately affect cell proliferation, apoptosis inhibition, angiogenesis, migration, adhesion, and invasion (Figure 2). ${ }^{80,81}$ While EGFR and its ligands are essential for normal mammary development in the presence or absence of the sex hormones estrogen and progesterone, ${ }^{80,81}$ dysregulation of EGFR leads to breast cancer and metastasis. EGFR is frequently expressed in basal-like breast cancer and is associated with brain metastasis, and the inhibition of EGFR and its ligands reduces breast cancer metastatic potential. ${ }^{82,83}$ Low doses of luteolin inhibit EGFR signaling in a dose-dependent manner by downregulating EGF-induced EGFR phosphorylation and subsequently decreasing the activation of the downstream kinases Akt, ERK, and p38 in MDA-MB-231 breast cancer cells. ${ }^{61}$ Similar findings have been reported in MCF7 cells in which moderate doses of luteolin abolished EGF-induced increased pEGFR, Akt, and ERK kinase activity, as well as the transcription factor STAT3 ${ }^{84}$ Increasing RTK activity, such as EGFR and HER2, leads to STAT3-induced tumor progression and metastasis. ${ }^{85,86}$ In combination therapy, luteolin and paclitaxel (a cytoskeletal drug) work together to increase expression of the death receptor Fas and reduce STAT3 activation, which results in increased apoptosis in MDA-MB-231 cells (Figure 3). ${ }^{87}$ These reports provide a multifaceted approach in which luteolin may reduce breast cancer invasion, metastasis, and colonization by itself or in combination with current chemotherapeutics through modulation of EGFR, PI3k/Akt, and MAPK activity, as well as JAK/STAT signaling.

\section{Insulin-like growth-factor I receptor}

IGF1R is instrumental in normal mammary development. However, in breast cancer IGF1R intrinsically confers survival properties in and of itself, as well as through other RTKs via crosstalk. ${ }^{88,89}$ Clinical studies utilizing monotherapeutic antibodies for EGFR and HER2 breast cancers have resulted in cancers gaining therapeutic resistance, in part due to IGF1R crosstalk. ${ }^{88,89}$ For example, after gaining resistance to gefitinib (an EGFR inhibitor) in MCF7 breast cancer cells, IGF1R dimerizes with EGFR and rescues downstream kinase activity. ${ }^{90}$ In the same cell line, albeit 
not a chemotherapeutically resistant version, luteolin abrogates IGF-induced phosphorylation of IGF1R, and the loss in IGFR activity is accompanied by a decrease in Akt but not ERK activity. ${ }^{91}$ Considering the ability of luteolin to suppress IGF1R and EGFR pathways as described, luteolin may be able to combat TKI drug-resistant breast cancer. ${ }^{91}$ Interestingly, Wang et al went on to implicate the transcription factor ER $\alpha$ as the mechanism of action. ${ }^{91}$ They showed that silencing ER $\alpha$ ameliorated luteolin inhibition of IGF-induced responses. ${ }^{91}$ Conventionally speaking, estrogen-induced proliferation is determined by the $E R \alpha: \beta$ ratio, with ER $\alpha$ acting in a proproliferative manner and ER $\beta$ being a functional antagonist. ${ }^{92,93}$ In regard to this, luteolin has been shown to bind irreversibly to estrogen elements ${ }^{94}$ and have antiestrogenic or weak estrogenic effects at a similar dosage to that used to inhibit the aforementioned IGF1R pathway. ${ }^{95,96}$ These reports suggest that luteolin may antagonize IGF-induced $\mathrm{ER} \alpha$-mediated proliferation by acting as an ER $\alpha$-competitive inhibitor, resulting in Akt pathway attenuation.

\section{Luteolin-mediated apoptosis}

The canonical apoptotic pathways include an intrinsic and extrinsic route (Figure 3). The intrinsic apoptotic pathway is mediated by Bcl-2 family members in response to myriad nonreceptor stimuli that ultimately induce changes in mitochondrial membrane integrity, resulting in apoptosis. Bcl-2 family members control apoptosis through varying amounts of pro- and antiapoptotic Bcl-2 proteins (Bad, Bax, BAK, Bcl-2, Bcl-xL), ${ }^{97}$ essentially acting like a pan balance in determining cell fate. When cytoplasmic Bad increases, $\mathrm{Bcl}-2$ and Bcl-xL dissociate from Bax and BAK and bind to Bad. ${ }^{97}$ In doing so, Bax and BAK are free to integrate into the mitochondrial membrane, decreasing its integrity, and initiate mitochondrial-mediated apoptosis via caspase-9 (Figure 3). ${ }^{97}$ In the extrinsic pathway, activated death receptors (DRs) (Fas, TNFR, TRAIL) signal the formation of the death-inducing signaling complex, which subsequently initiates the caspase cascade through caspase- 8 and caspase-10.97

In MCF7 breast cancer cells, luteolin induces apoptosis through both extrinsic and intrinsic pathways. Luteolin increases DR expression, ${ }^{76,87}$ activates caspase- 8 , and subsequently induces caspase- 3 activity in the extrinsic apoptotic pathway. In the intrinsic path, Park et al showed luteolin increases Bax expression and decreases Bcl-2 expression, which in turn decreases mitochondrial membrane integrity, contributing to increased caspase-3 activity via caspase-9 activation. ${ }^{76}$ Additionally, in MDA-MB-231 cells, low doses of luteolin significantly increase the Bax:Bcl-xL ratio, favoring apoptosis.$^{61}$ Somewhat confounding are results concerning a luteolin-doxorubicin combination. Sato et al reported that, low-dose luteolin ameliorated doxorubicin (topoisomerase inhibitor) cytotoxicity in part by decreasing doxorubicininduced reactive oxygen species (ROS) and increasing Bcl-2 in MCF7 cells. ${ }^{98}$ Flavonoids, including luteolin, are well known for their antioxidative properties; ${ }^{99}$ however, moderate concentrations of luteolin have been shown to induce ROS in cancer cells (Figure 3). ${ }^{100}$ In this case, luteolin is likely acting as an antioxidant, but this maybe a dose-dependent effect.

As previously mentioned, luteolin can modify p 53 activity indirectly ${ }^{62,65}$ or directly, ${ }^{68}$ and p53 mediates the intrinsic apoptotic pathway by regulating Bcl-2 family proteins, specifically through inhibition of Bcl-2 and Bax integration into the mitochondrial membrane ${ }^{97}$ In MCF7 cells, luteolin increased p53 protein levels, which results in the release of the intrinsic apoptosis mediator cytochrome $\mathrm{C}$ and PARP activation. ${ }^{101}$ Additional reports confirm the ability of luteolin to increase 553 and decrease Bcl-2 mRNA in MDA-MB-231 cells. ${ }^{102}$ This presents a novel avenue for luteolin to reduce metastatic colony formation, especially when considering a significant amount of breast cancer contains wild-type P53. ${ }^{103,104}$ However, the mechanism by which luteolin stabilizes the tumor-suppressor protein p53 and subsequently causes apoptosis in breast cancer is ambiguous.

\section{FOXO-dependent apoptosis}

In MCF7 breast cancer cells, luteolin shows a marked suppression in active Akt protein, cell migration, and subsequently an increase in apoptosis. ${ }^{101,105}$ Observations suggest that luteolin decreases cytosolic FOXO3a levels, while it increases nuclear FOXO3a levels over 48 hours. ${ }^{101}$ Lin et al hypothesized that the nuclear accumulation of FOXO3a was due to the observed loss in Akt (Figure 2) ${ }^{101}$ In support, recent evidence suggests that Akt inhibition can promote FOXO3a-dependent apoptosis. ${ }^{106}$ Unphosphorylated nuclear FOXO3a acts as a transcription factor to orchestrate p 21 and p27 transcription, in addition to BIM-dependent apoptosis. ${ }^{107}$ PI3K/Akt-pathway inhibition would prevent phosphorylation of the tumor suppressor FOXO3a, which causes its nuclear exportation and proteolytic degradation.

\section{FAS-induced apoptosis}

Repressing fatty-acid synthesis in breast cancer has been shown to induce programmed cell death (Figure 3). ${ }^{108}$ In MDA-MB-231 cells, luteolin reduces FAS (an instrumental lipogenic enzyme) activity, achieving a nearly $50 \%$ reduction in cell viability at relatively low doses. ${ }^{109}$ In liver cancer 
cells, luteolin decreases both SREB-1 and FAS mRNA. ${ }^{110}$ In agreement with the luteolin studies, inhibition of MAPK or PI3K signals in breast cancer cells results in decreased SREB-1 transcription and a corresponding decrease in FAS mRNA and protein. ${ }^{11}$ In vivo targeted inhibition of either FAS or SREB-1 has also been shown to reduce tumor burden substantially. ${ }^{112}$ Taken together, these studies suggest that luteolin suppresses FAS through Akt inhibition.

\section{Conclusion}

Prevention and treatment of metastatic breast cancer will ultimately lead to increased and sustained quality of life for breast cancer patients. Metastasis requires breast cancer cells to undergo morphological changes, migrate, and then colonize at distant sites. Playing a central role is Akt, and its hyperactivity is involved in increased cancer metastasis. ${ }^{113}$ RTKs regulate Akt activity; however, constitutively active Akt can occur in the absence of RTK signaling by deactivating the tumor suppressor PTEN, a possible TKI-escape mechanism. ${ }^{114}$ The ability of luteolin preferentially to disrupt RTKs and/or the downstream effectors Akt, ERK, and STAT3 activity is seen extensively in breast cancer (Table 1) and others. ${ }^{32,115-117}$ These studies provide compelling evidence that luteolin can palliate RTK-induced invasion, metastasis, and colonization. ${ }^{32,116,118}$ Furthermore, luteolin not only inhibits RTK/Akt activity but it may also reestablish therapeutic potency in breast cancers..$^{62,119,120}$ Of note, most of the mechanistic experiments performed utilizing luteolin have been in the metastatic breast cancer cell lines MDA-MB-231 and MCF7 (Table 1). Further studies utilizing the T47D and SKBR3 cell lines may add to the mechanisms of action by which luteolin suppresses metastatic breast cancer in vivo.

\section{Disclosure}

The author reports no conflicts of interest in this work.

\section{References}

1. Siegel RL, Miller KD, Jemal A. Cancer statistics, 2017. CA Cancer J Clin. 2017;67(1):7-30.

2. Paget $\mathrm{S}$. The distribution of secondary growths in cancer of the breast. Lancet. 1889;133(3421):571-573.

3. Gupta GP, Massagué J. Cancer metastasis: building a framework. Cell. 2006;127(4):679-695.

4. Steeg PS. Tumor metastasis: mechanistic insights and clinical challenges. Nat Med. 2006;12(8):895-904.

5. Fidler IJ. The pathogenesis of cancer metastasis: the 'seed and soil' hypothesis revisited. Nat Rev Cancer. 2003;3(6):453-458.

6. Weigelt B, Peterse JL, Van't Veer LJ. Breast cancer metastasis: markers and models. Nat Rev Cancer. 2005;5(8):591.

7. Lopez-Lazaro M. Distribution and biological activities of the flavonoid luteolin. Mini Rev Med Chem. 2009;9(1):31-59.
8. Hanahan D, Weinberg RA. Hallmarks of cancer: the next generation. Cell. 2011;144(5):646-674.

9. Price DJ, Miralem T, Jiang S, Steinberg R, Avraham H. Role of vascular endothelial growth factor in the stimulation of cellular invasion and signaling of breast cancer cells. Cell Growth Differ. 2001;12(3):129-135.

10. Ferrara N, Gerber HP, LeCouter J. The biology of VEGF and its receptors. Nat Med. 2003;9(6):669-676.

11. Hanahan D, Folkman J. Patterns and emerging mechanisms of the angiogenic switch during tumorigenesis. Cell. 1996;86(3):353-364.

12. Hicklin DJ, Ellis LM. Role of the vascular endothelial growth factor pathway in tumor growth and angiogenesis. J Clin Oncol. 2005;23(5):1011-1027.

13. Zhao D, Pan C, Sun J, et al. VEGF drives cancer-initiating stem cells through VEGFR-2/Stat3 signaling to upregulate Myc and Sox2. Oncogene. 2015;34(24):3107-3119.

14. Cook MT, Liang Y, Besch-Williford C, Hyder SM. Luteolin inhibits lung metastasis, cell migration, and viability of triple-negative breast cancer cells. Breast Cancer (Dove Med Press). 2017;9:9-19.

15. Sun DW, Zhang HD, Mao L, et al. Luteolin inhibits breast cancer development and progression in vitro and in vivo by suppressing notch signaling and regulating miRNAs. Cell Physiol Biochem. 2015;37(5):1693-1711.

16. Cook MT, Liang Y, Besch-Williford C, Goyette S, Mafuvadze B, Hyder SM. Luteolin inhibits progestin-dependent angiogenesis, stem cell-like characteristics, and growth of human breast cancer xenografts. SpringerPlus. 2015;4:444.

17. Pratheeshkumar P, Son YO, Budhraja A, et al. Luteolin inhibits human prostate tumor growth by suppressing vascular endothelial growth factor receptor 2-mediated angiogenesis. PLoS One. 2013;7(12):e52279.

18. Lin D, Kuang G, Wan J, et al. Luteolin suppresses the metastasis of triple-negative breast cancer by reversing epithelial-to-mesenchymal transition via downregulation of $\beta$-catenin expression. Oncol Rep. 2017;37(2):895-902.

19. Zang M, Hu L, Zhang B, et al. Luteolin suppresses angiogenesis and vasculogenic mimicry formation through inhibiting Notch1VEGF signaling in gastric cancer. Biochem Biophys Res Commun. 2017;490(3):913-919.

20. Bagli E, Stefaniotou M, Morbidelli L, et al. Luteolin inhibits vascular endothelial growth factor-induced angiogenesis; inhibition of endothelial cell survival and proliferation by targeting phosphatidylinositol 3'-kinase activity. Cancer Res. 2004;64(21):7936-7946.

21. Ravishankar D, Watson KA, Boateng SY, Green RJ, Greco F, Osborn HM. Exploring quercetin and luteolin derivatives as antiangiogenic agents. Eur J Med Chem. 2015;97:259-274.

22. Zhu M, Chen D, Li D, et al. Luteolin inhibits angiotensin II-induced human umbilical vein endothelial cell proliferation and migration through downregulation of Src and Akt phosphorylation. Circ J. 2013;77(3):772-779.

23. Hiraoka N, Allen E, Apel IJ, Gyetko MR, Weiss SJ. Matrix metalloproteinases regulate neovascularization by acting as pericellular fibrinolysins. Cell. 1998;95(3):365-377.

24. Deryugina EI, Quigley JP. Matrix metalloproteinases and tumor metastasis. Cancer Metastasis Rev. 2006;25(1):9-34.

25. Merdad A, Karim S, Schulten HJ, et al. Expression of matrix metalloproteinases (MMPs) in primary human breast cancer: MMP-9 as a potential biomarker for cancer invasion and metastasis. Anticancer Res. 2014;34(3):1355-1366.

26. Ende C, Gebhardt R. Inhibition of matrix metalloproteinase-2 and-9 activities by selected flavonoids. Planta Med. 2004;70(10):1006-1008.

27. Park SH, Kim JH, Lee DH, et al. Luteolin 8-C- $\beta$-fucopyranoside inhibits invasion and suppresses TPA-induced MMP-9 and IL-8 via ERK/AP-1 and ERK/NF-אB signaling in MCF-7 breast cancer cells. Biochimie. 2013;95(11):2082-2090.

28. Vandooren J, van den Steen PE, Opdenakker G. Biochemistry and molecular biology of gelatinase B or matrix metalloproteinase-9 (MMP9): the next decade. Crit Rev Biochem Mol Biol. 2013;48(3):222-272. 
29. Jiang Y, Xie K, Huo H, Wang L, Zou W, Xie M. [Inhibitory effect of luteolin on the angiogenesis of chick chorioallantoic membrane and invasion of breast cancer cells via downregulation of AEG-1 and MMP-2]. Sheng Li Xue Bao. 2013;65(5):513-518. Chinese.

30. Lu X, Li Y, Xiao X, Li X. [Inhibitory effects of luteolin on human gastric carcinoma xenografts in nude mice and its mechanism]. Zhonghua Yi Xue Za Zhi. 2013;93(2):142-146. Chinese.

31. Pandurangan A, Dharmalingam P, Sadagopan S, Ganapasam S. Luteolin inhibits matrix metalloproteinase 9 and 2 in azoxymethane-induced colon carcinogenesis. Hum Exp Toxicol. 2014;33(11):1176-1185.

32. Huang X, Dai S, Dai J, et al. Luteolin decreases invasiveness, deactivates STAT3 signaling, and reverses interleukin-6 induced epithelial-mesenchymal transition and matrix metalloproteinase secretion of pancreatic cancer cells. Onco Targets Ther. 2015;8:2989.

33. Köhrmann A, Kammerer U, Kapp M, Dietl J, Anacker J. Expression of matrix metalloproteinases (MMPs) in primary human breast cancer and breast cancer cell lines: New findings and review of the literature. BMC Cancer. 2009;9:188.

34. Turley EA, Noble PW, Bourguignon LY. Signaling properties of hyaluronan receptors. J Biol Chem. 2002;277(7):4589-4592.

35. Sheridan C, Kishimoto H, Fuchs RK, et al. CD44+/CD24-breast cancer cells exhibit enhanced invasive properties: an early step necessary for metastasis. Breast Cancer Res. 2006;8(5):R59.

36. Charafe-Jauffret E, Ginestier C, Iovino F, et al. Breast cancer cell lines contain functional cancer stem cells with metastatic capacity and a distinct molecular signature. Cancer Res. 2009;69(4):1302-1313.

37. Draffin JE, McFarlane S, Hill A, Johnston PG, Waugh DJ. CD44 potentiates the adherence of metastatic prostate and breast cancer cells to bone marrow endothelial cells. Cancer Res. 2004;64(16):5702-5711.

38. Kuppusamy U, Khoo H, Das N. Structure-activity studies of flavonoids as inhibitors of hyaluronidase. Biochem Pharmacol. 1990;40(2): 397-401.

39. Reipas KM, Law JH, Couto N, et al. Luteolin is a novel p90 ribosomal S6 kinase (RSK) inhibitor that suppresses Notch4 signaling by blocking the activation of Y-box binding protein-1 (YB-1). Oncotarget. 2013;4(2):329-345.

40. Tsai PH, Cheng CH, Lin CY, et al. Dietary flavonoids luteolin and quercetin suppressed cancer stem cell properties and metastatic potential of isolated prostate cancer cells. Anticancer Res. 2016;36(12):6367-6380.

41. Tu DG, Lin WT, Yu CC, et al. Chemotherapeutic effects of luteolin on radio-sensitivity enhancement and interleukin-6/signal transducer and activator of transcription 3 signaling repression of oral cancer stem cells. J Formos Med Assoc. 2016;115(12):1032-1038.

42. Hojilla C, Mohammed F, Khokha R. Matrix metalloproteinases and their tissue inhibitors direct cell fate during cancer development. $\mathrm{Br}$ J Cancer. 2003;89(10):1817-1821.

43. Korkaya H, Liu S, Wicha MS. Breast cancer stem cells, cytokine networks, and the tumor microenvironment. $J$ Clin Invest. 2011;121(10):3804-3809.

44. Seelinger G, Merfort I, Schempp CM. Anti-oxidant, antiinflammatory and anti-allergic activities of luteolin. Planta Med. 2008;74(14):1667-1677.

45. Benoy IH, Salgado R, van Dam P, et al. Increased serum interleukin-8 in patients with early and metastatic breast cancer correlates with early dissemination and survival. Clin Cancer Res. 2004;10(21):7157-7162.

46. Choi HJ, Choi HJ, Chung TW, Ha KT. Luteolin inhibits recruitment of monocytes and migration of Lewis lung carcinoma cells by suppressing chemokine ( $\mathrm{C}-\mathrm{C}$ motif) ligand 2 expression in tumor-associated macrophage. Biochem Biophys Res Commun. 2016;470(1):101-106.

47. Zhan T, Rindtorff N, Boutros M. Wnt signaling in cancer. Oncogene. 2017;36(11):1461-1473

48. Lamouille S, Xu J, Derynck R. Molecular mechanisms of epithelialmesenchymal transition. Nat Rev Mol Cell Biol. 2014;15(3):178-196.

49. Tse JC, Kalluri R. Mechanisms of metastasis: epithelial-to-mesenchymal transition and contribution of tumor microenvironment. J Cell Biochem. 2007;101(4):816-829.
50. Nelson WJ, Nusse R. Convergence of Wnt, $\beta$-catenin, and cadherin pathways. Science. 2004;303(5663):1483-1487.

51. Clevers H. Wnt $/ \beta$-catenin signaling in development and disease. Cell. 2006;127(3):469-480.

52. Blanco MJ, Moreno-Bueno G, Sarrio D, et al. Correlation of Snail expression with histological grade and lymph node status in breast carcinomas. Oncogene. 2002;21(20):3241-3246.

53. Pandurangan AK, Dharmalingam P, Sadagopan SKA, Ramar M, Munusamy A, Ganapasam S. Luteolin induces growth arrest in colon cancer cells through involvement of Wnt/ $\beta$-catenin/GSK-3 $\beta$ signaling. J Environ Pathol Toxicol Oncol. 2013;32(2):131-139.

54. Chen J, Imanaka N, Griffin J. Hypoxia potentiates Notch signaling in breast cancer leading to decreased E-cadherin expression and increased cell migration and invasion. Br J Cancer. 2010;102(2):351-360.

55. Ranganathan $P$, Weaver KL, Capobianco AJ. Notch signalling in solid tumours: a little bit of everything but not all the time. Nat Rev Cancer. 2011;11(5):338-351.

56. Anjum R, Blenis J. The RSK family of kinases: emerging roles in cellular signalling. Nat Rev Mol Cell Biol. 2008;9(10):747-758.

57. Harrison H, Farnie G, Howell SJ, et al. Regulation of breast cancer stem cell activity by signaling through the Notch4 receptor. Cancer Res. 2010;70(2):709-718.

58. Espinosa $\mathrm{L}$, Inglés-Esteve J, Aguilera $\mathrm{C}$, Bigas A. Phosphorylation by glycogen synthase kinase- $3 \beta$ down-regulates Notch activity, a link for Notch and Wnt pathways. J Biol Chem. 2003;278(34):32227-32235.

59. Fang X, Yu SX, Lu Y, Bast RC, Woodgett JR, Mills GB. Phosphorylation and inactivation of glycogen synthase kinase 3 by protein kinase A. Proc Natl Acad Sci U S A. 2000;97(22):11960-11965.

60. Malumbres M, Barbacid M. Cell cycle, CDKs and cancer: a changing paradigm. Nat Rev Cancer. 2009;9(3):153-166.

61. Lee EJ, Oh SY, Sung MK. Luteolin exerts anti-tumor activity through the suppression of epidermal growth factor receptor-mediated pathway in MDA-MB-231 ER-negative breast cancer cells. Food Chem Toxicol. 2012;50(11):4136-4143.

62. Rao PS, Satelli A, Moridani M, Jenkins M, Rao US. Luteolin induces apoptosis in multidrug resistant cancer cells without affecting the drug transporter function: involvement of cell line-specific apoptotic mechanisms. Int J Cancer. 2012;130(11):2703-2714.

63. Chiang CT, Way TD, Lin JK. Sensitizing HER2-overexpressing cancer cells to luteolin-induced apoptosis through suppressing p21WAF1/ CIP1 expression with rapamycin. Mol Cancer Ther. 2007;6(7): 2127-2138.

64. Abbas T, Dutta A. P21 in cancer: intricate networks and multiple activities. Nat Rev Cancer. 2009;9(6):400-414.

65. Casagrande F, Darbon JM. Effects of structurally related flavonoids on cell cycle progression of human melanoma cells: regulation of cyclin-dependent kinases CDK2 and CDK1. Biochem Pharmacol. 2001;61(10):1205-1215.

66. Chowdhury AR, Sharma S, Mandal S, Goswami A, Mukhopadhyay S, Majumder HK. Luteolin, an emerging anti-cancer flavonoid, poisons eukaryotic DNA topoisomerase I. Biochem J. 2002;366(2):653-661.

67. Yamashita N, Kawanishi S. Distinct mechanisms of DNA damage in apoptosis induced by quercetin and luteolin. Free Radic Res. 2000;33(5):623-633.

68. Amin AR, Wang D, Zhang H, et al. Enhanced anti-tumor activity by the combination of the natural compounds (-)-epigallocatechin-3-gallate and luteolin potential role of p53. J Biol Chem. 2010;285(45):34557-34565.

69. Overton KW, Spencer SL, Noderer WL, Meyer T, Wang CL. Basal p21 controls population heterogeneity in cycling and quiescent cell cycle states. Proc Natl Acad Sci U S A. 2014;111(41):E4386-E4393.

70. Kobayashi T, Nakata T, Kuzumaki T. Effect of flavonoids on cell cycle progression in prostate cancer cells. Cancer Lett. 2002;176(1):17-23.

71. Cai X, Ye T, Liu C, et al. Luteolin induced G2 phase cell cycle arrest and apoptosis on non-small cell lung cancer cells. Toxicol In vitro. 2011;25(7):1385-1391. 
72. Li YM, Pan Y, Wei Y, et al. Upregulation of CXCR4 is essential for HER2-mediated tumor metastasis. Cancer Cell. 2004;6(5):459-469.

73. Ross JS, Slodkowska EA, Symmans WF, Pusztai L, Ravdin PM, Hortobagyi GN. The HER-2 receptor and breast cancer: ten years of targeted anti-HER-2 therapy and personalized medicine. Oncologist. 2009;14(4):320-368.

74. Way TD, Kao MC, Lin JK. Degradation of HER2/neu by apigenin induces apoptosis through cytochrome c release and caspase-3 activation in HER2/neu-overexpressing breast cancer cells. FEBS Lett. 2005;579(1):145-152.

75. Catzavelos C, Bhattacharya N, Ung YC, et al. Decreased levels of the cell-cycle inhibitor $\mathrm{p} 27^{\mathrm{Kip} 1}$ protein: prognostic implications in primary breast cancer. Nat Med. 1997;3(2):227-230.

76. Park SH, Ham S, Kwon TH, et al. Luteolin induces cell cycle arrest and apoptosis through extrinsic and intrinsic signaling pathways in MCF-7 breast cancer cells. J Environ Pathol Toxicol Oncol. 2014;33(3): 219-231.

77. Sergina NV, Rausch M, Wang D, et al. Escape from HER-family tyrosine kinase inhibitor therapy by the kinase-inactive HER3. Nature. 2007;445(7126):437-441.

78. Yakes FM, Chinratanalab W, Ritter CA, King W, Seelig S, Arteaga CL. Herceptin-induced inhibition of phosphatidylinositol-3 kinase and Akt Is required for antibody-mediated effects on p27, cyclin D1, and antitumor action. Cancer Res. 2002;62(14):4132-4141.

79. Zhang L, Yang F, Huang L, Liu A, Zhang J. Luteolin enhances the antitumor activity of lapatinib in human breast cancer cells. Biomed Res. 2017;28(11):4902-4907.

80. Sebastian J, Richards RG, Walker MP, et al. Activation and function of the epidermal growth factor receptor and erbB-2 during mammary gland morphogenesis. Cell Growth Differ. 1998;9(9):777-785.

81. Kenney NJ, Bowman A, Korach KS, Barrett JC, Salomon DS. Effect of exogenous epidermal-like growth factors on mammary gland development and differentiation in the estrogen receptor-alpha knockout (ERKO) mouse. Breast Cancer Res Treat. 2003;79(2):161-173.

82. Bos PD, Zhang XH, Nadal C, et al. Genes that mediate breast cancer metastasis to the brain. Nature. 2009;459(7249):1005-1009.

83. Hicks DG, Short SM, Prescott NL, et al. Breast cancers with brain metastases are more likely to be estrogen receptor negative, express the basal cytokeratin CK5/6, and overexpress HER2 or EGFR. Am J Surg Pathol. 2006;30(9):1097-1104.

84. Sui J, Xie K, Xie M. Inhibitory effect of luteolin on the proliferation of human breast cancer cell lines induced by epidermal growth factor. Sheng Li Xue Bao. 2016;68(1):27-34.

85. Bromberg J. Stat proteins and oncogenesis. J Clin Invest. 2002;109(9): 1139-1142.

86. Devarajan E, Huang S. STAT3 as a central regulator of tumor metastases. Cur Mol Med. 2009;9(5):626-633.

87. Yang MY, Wang CJ, Chen NF, Ho WH, Lu FJ, Tseng TH. Luteolin enhances paclitaxel-induced apoptosis in human breast cancer MDA-MB-231 cells by blocking STAT3. Chem Biol Interact. 2014;213:60-68.

88. Nahta R, Yuan LX, Zhang B, Kobayashi R, Esteva FJ. Insulin-like growth factor-I receptor/human epidermal growth factor receptor 2 heterodimerization contributes to trastuzumab resistance of breast cancer cells. Cancer Res. 2005;65(23):11118-11128.

89. Oliveira S, Schiffelers R, Storm G, Henegouwen P, Roovers R. Crosstalk between epidermal growth factor receptor-and insulin-like growth factor-1 receptor signaling: implications for cancer therapy. Curr Cancer Drug Targets. 2009;9(6):748-760.

90. Jones HE, Goddard L, Gee JM, et al. Insulin-like growth factor-I receptor signalling and acquired resistance to gefitinib (ZD1839; Iressa) in human breast and prostate cancer cells. Endocr Relat Cancer. 2004;11(4):793-814.

91. Wang LM, Xie KP, Huo HN, Shang F, Zou W, Xie MJ. Luteolin inhibits proliferation induced by IGF-1 pathway dependent $\mathrm{ER} \alpha$ in human breast cancer MCF-7 cells. Asian Pac J Cancer Prev. 2012;13(4):1431-1437.
92. Ström A, Hartman J, Foster JS, Kietz S, Wimalasena J, Gustafsson JA. Estrogen receptor $\beta$ inhibits $17 \beta$-estradiol-stimulated proliferation of the breast cancer cell line T47D. Proc Natl Acad Sci US A. 2004;101(6):1566-1571.

93. Covaleda AM, van den Berg H, Vervoort J, et al. Influence of cellular $\mathrm{ER} \alpha / \mathrm{ER} \beta$ ratio on the ER $\alpha$-agonist induced proliferation of human T47D breast cancer cells. Toxicol Sci. 2008;105(2):303-311.

94. Markaverich BM, Roberts RR, Alejandro MA, Johnson GA, Middleditch BS, Clark JH. Bioflavonoid interaction with rat uterine type II binding sites and cell growth inhibition. J Steroid Biochem. 1988;30(1-6):71-78.

95. Le Bail JC, Varnat F, Nicolas JC, Habrioux G. Estrogenic and antiproliferative activities on MCF-7 human breast cancer cells by flavonoids. Cancer Lett. 1998;130(1):209-216.

96. Markaverich BM, Shoulars K, Rodriguez MA. Luteolin regulation of estrogen signaling and cell cycle pathway genes in MCF-7 human breast cancer cells. Int J Biomed Sci. 2011;7(2):101-111.

97. Elmore S. Apoptosis: a review of programmed cell death. Toxicol Pathol. 2007;35(4):495-516.

98. Sato Y, Sasaki N, Saito M, Endo N, Kugawa F, Ueno A. Luteolin attenuates doxorubicin-induced cytotoxicity to mcf-7 human breast cancer cells. Biol Pharm Bul. 2015;38(5):703-709.

99. Rice-Evans CA, Miller NJ, Paganga G. Structure-antioxidant activity relationships of flavonoids and phenolic acids. Free Radic Biol Med. 1996;20(7):933-956.

100. Ju W, Wang X, Shi H, Chen W, Belinsky SA, Lin Y. A critical role of luteolin-induced reactive oxygen species in blockage of tumor necrosis factor-activated nuclear factor- $\kappa \mathrm{B}$ pathway and sensitization of apoptosis in lung cancer cells. Mol Pharmacol. 2007;71(5):1381-1388.

101. Lin CH, Chang CY, Lee KR, Lin HJ, Chen TH, Wan L. Flavones inhibit breast cancer proliferation through the Akt/FOXO3a signaling pathway. BMC Cancer. 2015;15:958.

102. Momtazi-Borojeni AA, Behbahani M, Sadeghi-Aliabadi H. Antiproliferative activity and apoptosis induction of crude extract and fractions of Avicennia marina. Iran J Basic Med Sci. 2013;16(11):1203-1208.

103. Allred DC, Clark GM, Elledge R, et al. Association of p53 protein expression with tumor cell proliferation rate and clinical outcome in node-negative breast cancer. J Natl Cancer Inst. 1993;85(3):200-206.

104. Sjögren S, Inganäs $M$, Norberg $T$, et al. The p53 gene in breast cancer: prognostic value of complementary DNA sequencing versus immunohistochemistry. J Natl Cancer Inst. 1996;88(3-4):173-182.

105. Jeon YW, Suh YJ. Synergistic apoptotic effect of celecoxib and luteolin on breast cancer cells. Oncol Rep. 2013;29(2):819-825.

106. Das T, Suman S, Alatassi H, Ankem M, Damodaran C. Inhibition of AKT promotes FOXO3a-dependent apoptosis in prostate cancer. Cell Death Dis. 2016;7(2):e2111.

107. Sunters A, de Mattos SF, Stahl M, et al. FoxO3a transcriptional regulation of Bim controls apoptosis in paclitaxel-treated breast cancer cell lines. J Biol Chem. 2003;278(50):49795-49805.

108. Pizer ES, Jackisch C, Wood FD, Pasternack GR, Davidson NE, Kuhajda FP. Inhibition of fatty acid synthesis induces programmed cell death in human breast cancer cells. Cancer Res. 1996;56(12):2745-2747.

109. Brusselmans K, Vrolix R, Verhoeven G, Swinnen JV. Induction of cancer cell apoptosis by flavonoids is associated with their ability to inhibit fatty acid synthase activity. J Biol Chem. 2005;280(7):5636-5645.

110. Liu JF, Ma Y, Wang Y, Du ZY, Shen JK, Peng HL. Reduction of lipid accumulation in HepG2 cells by luteolin is associated with activation of AMPK and mitigation of oxidative stress. Phytother Res. 2011;25(4):588-596.

111. Yang YA, Han WF, Morin PJ, Chrest FJ, Pizer ES. Activation of Fatty acid synthesis during neoplastic transformation: role of mitogenactivated protein kinase and phosphatidylinositol 3-kinase. Exp Cell Res. 2002;279(1):80-90.

112. Guo D, Prins RM, Dang J, et al. EGFR signaling through an AktSREBP-1-dependent, rapamycin-resistant pathway sensitizes glioblastomas to antilipogenic therapy. Sci Signal. 2009;2(101):ra82. 
113. Xue G, Hemmings BA. PKB/Akt-dependent regulation of cell motility. J Natl Cancer Inst. 2013;105(6):393-404.

114. Sos ML, Koker M, Weir BA, et al. PTEN loss contributes to erlotinib resistance in EGFR-mutant lung cancer by activation of Akt and EGFR. Cancer Res. 2009;69(8):3256-3261.

115. Fang J, Zhou Q, Shi Xl, Jiang BH. Luteolin inhibits insulin-like growth factor 1 receptor signaling in prostate cancer cells. Carcinogenesis. 2007;28(3):713-723.

116. Lee LT, Huang YT, Hwang JJ, et al. Transinactivation of the epidermal growth factor receptor tyrosine kinase and focal adhesion kinase phosphorylation by dietary flavonoids: effect on invasive potential of human carcinoma cells. Biochem Pharmacol. 2004;67(11):2103-2114.

117. Shih YL, Liu HC, Chen CS, et al. Combination treatment with luteolin and quercetin enhances antiproliferative effects in nicotine-treated MDA-MB-231 cells by down-regulating nicotinic acetylcholine receptors. J Agric Food Chem. 2009;58(1):235-241.

118. Huang YT, Hwang JJ, Lee PP, et al. Effects of luteolin and quercetin, inhibitors of tyrosine kinase, on cell growth and metastasis-associated properties in A431 cells overexpressing epidermal growth factor receptor. Br J Pharmacol. 1999;128(5):999-1010.
119. Tu SH, Ho CT, Liu MF, et al. Luteolin sensitises drug-resistant human breast cancer cells to tamoxifen via the inhibition of cyclin E2 expression. Food Chem. 2013;141(2):1553-1561.

120. van Zanden JJ, Geraets L, Wortelboer HM, van Bladeren PJ, Rietjens IM, Cnubben NH. Structural requirements for the flavonoidmediated modulation of glutathione S-transferase P1-1 and GS-X pump activity in MCF7 breast cancer cells. Biochem Pharmacol. 2004;67(8):1607-1617.

121. Coleman DT, Bigelow R, Cardelli JA. Inhibition of fatty acid synthase by luteolin post-transcriptionally down-regulates c-Met expression independent of proteosomal/lysosomal degradation. Mol Cancer Ther. 2009;8(1):214-224.

122. Kim MJ, Woo JS, Kwon CH, Kim JH, Kim YK, Kim KH. Luteolin induces apoptotic cell death through AIF nuclear translocation mediated by activation of ERK and $\mathrm{p} 38$ in human breast cancer cell lines. Cell Biol Int. 2012;36(4):339-344.

123. Du GJ, Song ZH, Lin HH, Han XF, Zhang S, Yang YM. Luteolin as a glycolysis inhibitor offers superior efficacy and lesser toxicity of doxorubicin in breast cancer cells. Biochem Biophys Res Commun. 2008;372(3):497-502.
Breast Cancer - Targets and Therapy

\section{Publish your work in this journal}

Breast Cancer - Targets and Therapy is an international, peerreviewed open access journal focusing on breast cancer research, identification of therapeutic targets and the optimal use of preventative and integrated treatment interventions to achieve improved outcomes, enhanced survival and quality of life for the cancer patient.

\section{Dovepress}

The manuscript management system is completely online and includes a very quick and fair peer-review system, which is all easy to use. Visit http://www.dovepress.com/testimonials.php to read real quotes from published authors.

Submit your manuscript here: https://www.dovepress.com/breast-cancer---targets-and-therapy-journal 